\title{
IDENTIFIKASI BORAKS PADA MAKANAN PEMPEK YANG DIJUAL PEDAGANG DI JALAN DURIAN KELURAHAN LABUH BARU KECAMATAN PAYUNG SEKAKI PEKANBARU
}

\author{
Yulia Yesti ${ }^{*}$, Syafila Rahayu ${ }^{2}$ \\ ${ }^{1}$ STIKes Fort De Kock Bukittinggi \\ ${ }^{2}$ Mahasiswi Akademi Analis Kesehatan Fajar Pekanbaru \\ *E-mail: iyulcongeh@gmail.com
}

\begin{abstract}
ABSTRAK
Bahan tambahan kimia dilarang penggunaannya dalam makanan tetapi kenyataannya sampai saat ini masih beredar dan dijual bebas dalam nama lain, salah satunya boraks. Penggunaan boraks dalam waktu lama dan jumlah yang banyak dapat menyebabkan kanker. Tujuan penelitian ini untuk mengetahui ada tidaknya boraks pada pempek yang dijual di jalan Durian Kelurahan Labuh Baru Kecamatan Payung Sekaki Pekanbaru. Jenis penelitian ini adalah analitik kualitatif. Populasi penelitian ini adalah Pempek yang diambil di jalan Durian Kelurahan Labuh Baru Kecamatan Payung Sekaki Pekanbaru. Teknik pengambilan sampel diambil sebanyak 1 penjual pempek yang berada di jalan durian yang dilakukan 3 kali pengulangan. Dari penelitian identifikasi boraks pada pempek yang diambil dari satu pedagang yang dilakukan tiga kali pengulangan didapatkan hasil positif mengandung boraks.
\end{abstract}

Kata kunci: Borak, Pempek

\section{ABSTRACT}

Chemical additives are banned to use in food, but it still sold freely in another name, which called pijer. The use of borax in a long time and large amounts can cause cancer. The purpose of this study was to determine avaulibility of borax on pempek that was sold in jalan durian Kelurahan Labuh Baru Kecamatan Payung Sekaki Pekanbaru. Type of research is a qualitative analytical. The population were pempek east sellers on jalan durian Kelurahan Labuh Baru Kecamatan Payung Sekaki Pekanbaru. The sampling technique was taken as much as one sellers pempek who are on the jalan durian performed three repetitions. Borax identification of research on pempek taken from a trader who performed three repetitions of positive results obtained containing borax.

Keywords $\quad$ : Borax, Pempek 


\section{PENDAHULUAN}

Makanan adalah salah satu kebutuhan dasar manusia. Sebagai kebutuhan dasar makanan tersebut harus mengandung zat gizi untuk dapat memenuhi fungsinya dan aman dikonsumsi karena makanan yang tidak aman dapat menimbulkan gangguan kesehatan bahkan keracunan. Banyaknya bahan tambahan makanan dalam bentuk lebih murni dan tersedia secara komersil dengan harga yang relatif murah akan mendorong meningkatnya pemakaian bahan tambahan makanan yang berarti meningkatkan konsumsi bahan tersebut bagi setiap individu (Tristianingsih, 2012). Tujuan penambahan zat tambahan makanan adalah untuk memperbaiki karakter pangan agar mutunya meningkat. Zat tambahan makanan tersebut dapat berupa penyedap contohnya adalah Monosodium Glutamate (MSG), asam atau garam benzoat untuk pengawet produk buah-buahan, kecap, keju dan margarin, asam askorbat sebagai antioksidan untuk produk daging, ikan beku dan buahbuahan kaleng, karamel untuk mewarnai jamur kaleng, brilliant blue FCF untuk mewarnai es krim (Alsuhendra \& Ridawati, 2013).

Pada umumnya dalam pengelolaan makanan selalu diusahakan untuk menghasilkan produk makanan yang disukai dan berkualitas baik. Untuk mendapatkan makanan seperti yang diinginkan maka sering pada proses pembuatannya dilakukan penambahan "bahan tambahan pangan (BTP)" yang disebut zat aktif kimia (food additive) (Widyaningsih, 2006). Bahan tambahan kimia yang dilarang penggunannya dalam makanan menurut Menteri RI adalah asam boraks atau boraks, asam salisilat, diethylprocarbonate, dulcin, potassium chlorate, chloramphenicol, minyak sayur terbrominasi, nitrofurazon, dan formaldehid.

Bahan tambahan kimia yang dilarang tidak disertai dengan batas maksimum penggunaan karena secara umum digolongkan ke dalam senyawa berbahaya bagi kesehatan tubuh. Bahan tambahan kimia yang dilarang penggunaannya dalam makanan tetapi kenyataannya sampai saat ini masih beredar dan dijual bebas dalam nama lain, salah satunya adalah senyawa bor yang dijual dengan nama boraks. Penggunaan boraks dalam waktu lama dan jumlah yang banyak dapat menyebabkan kanker (Cahyadi, 2009).

Boraks adalah senyawa berbentuk kristal putih tidak berbau dan stabil pada suhu ruangan. Boraks merupakan senyawa kimia dengan nama natrium tetraboraks $\left(\mathrm{NaB}_{4} \mathrm{O}_{7} \cdot 10 \mathrm{H}_{2} \mathrm{O}\right)$. Jika larut dalam air akan menjadi hidroksida dan asam boraks $\left(\mathrm{H}_{3} \mathrm{BO}_{3}\right)$. Boraks atau asam boraks biasanya digunakan untuk bahan pembuat 
deterjen dan antiseptik. Mengkonsumsi makanan yang mengandung

boraks tidak berakibat buruk secara langsung, tetapi boraks akan menumpuk sedikit demi sedikit karena diserap dalam tubuh konsumen secara kumulatif. Larangan penggunaan boraks juga diperkuat dengan adanya Peraturan Menteri Kesehatan RI No. 772 / Menkes / Per / IX / 88 No. 1168 / Menkes / PER / X / 1999 menyatakan secara umum BTP adalah bahan yang biasanya tidak digunakan sebagai makanan dan biasanya bukan merupakan komponen khas makanan mempunyai dan tidak mempunyai nilai gizi yang dengan sengaja ditambahkan ke dalam makanan untuk maksud teknologi pada pembuatan, pengolahan, penyiapan, perlakuan, pengepakan, pengemasan dan penyimpanan (Cahyadi, 2009).

Dalam penelitian yang dilakukan oleh Nasution (2009), tentang boraks pada makanan berupa mie basah, lontong, bakso, pempek dan kerupuk udang yang diambil secara acak di Pasar SMEP, Tugu, Bambu Kuning, Kampung

Sawah, dan swalayan Bandar Lampung, dari 30 contoh mie basah, $84 \%$ positif mengandung boraks. Dari 9 sampel lontong, 11,1\% mengandung boraks, dan dari 13 sampel pempek, 85\% juga mengandung boraks, dari 12 sampel kerupuk udang, $100 \%$ positif mengandung boraks.

Pempek atau empek-empek merupakan makanan khas Palembang yang terbuat dari ikan dan sagu. Di Jalan Durian Kelurahan Labuh Baru Kecamatan Payung Sekaki Pekanbaru juga terdapat penjual pempek. Kejadian ini memberi rasa keingintahuan penulis untuk mengidentifikasi ada atau tidaknya bahan tambahan pangan boraks yang ditambahkan pada pempek tersebut.

Berdasarkan uraian di atas, maka penulis tertarik melakukan penelitian dengan judul "Identifikasi Borak pada Makanan Pempek yang Dijual Pedagang di Jalan Durian Kelurahan Labuh Baru Kecamatan Payung Sekaki Pekanbaru" karena penulis ingin mengetahui apakah pempek di jalan durian itu mengandung pengawet boraks karena dicurigai pempek tersebut terlihat berbentuk kenyal, keras dan tahan lama.

\section{TINJAUAN TEORITIS}

Bahan tambahan makanan (BTM) adalah bahan atau campuran bahan yang secara alami bukan merupakan bagian dari bahan baku pangan, tetapi ditambahkan ke dalam pangan untuk mempengaruhi sifat atau bentuk bahan pangan (Hariadi, 2009). Pengertian bahan tambahan makanan dalam Peraturan Menteri Kesehatan RI No.722/Menkes/Per/IX/1988 dan No. 1168/Menkes/Per/X/1999 secara umum 
adalah bahan yang biasanya tidak digunakan sebagai makanan dan biasanya bukan merupakan komponen khas makanan, mempunyai atau tidak mempunyai nilai gizi (Cahyadi, 2009). Bahan tambahan makanan adalah bukan bahan yang ditambahkan dan dicampurkan sewaktu pengolahan makanan untuk meningkatkan mutu (Rohman, 2007). Menurut Sartono (2001), berdasarkan peraturan Menteri Kesehatan Republik Indonesia No. 722/Menkes/Per/IX/1988 tentang bahan tambahan pangan yang dilarang digunakan dalam makanan adalah:

1. Asam boraks

2. Asam salisilat

3. Dietilpirokarbonat

4. Dulsin

5. Kalium klorat

6. Kloramfenikol

7. Formalin

Suatu bahan pengawet mungkin efektif untuk mengawetkan pangan tertentu, tetapi tidak efektif untuk mengawetkan pangan lainnya karena pangan mempunyai sifat yang berbeda-beda. Pada saat ini, masih banyak ditemukan penggunaan bahanbahan pengawet yang dilarang untuk pangan dan berbahaya bagi kesehatan, seperti boraks dan formalin (Cahyadi, 2009).

\section{METODE PENELITIAN}

\section{Jenis dan Desain Penelitian}

Penelitian bersifat eksperimental laboratory dengan analisa Kualitatif, yaitu mengidentifikasi apakah pempek yang dijual di jalan Durian Kelurahan Labuh Baru Kecamatan Payung SekakiPekanbaru mengandung senyawa borak sebagai pengawet.

\section{Waktu Dan Tempat Penelitian}

Penelitian ini akan dilaksanakan pada bulan Februari sampai April 2015, bertempat di Laboratorium Kimia Akademi Analis Kesahatan (AAK) Yayasan Fajar Pekanbaru.

\section{Populasi dan Sampel penelitian}

Populasi dalam penelitian ini adalah Pempek yang dijual di Jalan Durian Kelurahan Labuh Baru Kecamatan Payung Sekaki Pekanbaru.

Sampel yang digunakan dalam penelitian ini adalah tiga sampel Pempek yang diambil di Jalan Durian Kelurahan Labuh Baru Kecamatan Payung Sekaki Pekanbaru dengan $3 x$ pengulangan.

\footnotetext{
Alat dan Bahan

Alat yang digunakan dalam penelitian ini, plat tetes, penanggas air, tanur, lumpang dan alu, hot plat, kertas saring dan gelas
} 
kimia yang biasa digunakan di Laboratorium.

Bahan yang digunakan dalam penelitian ini, kunyit 10 gram, $\mathrm{Na}_{2} \mathrm{~B}_{4} \mathrm{O}_{7} \cdot 10 \mathrm{H}_{2} \mathrm{O}, \mathrm{HCl}$ 1:1, dan $\mathrm{Na}_{2} \mathrm{CO}_{3} 10 \%$.

\section{Prosedur Kerja}

\section{Pembuatan Blanko}

$5 \mathrm{~mL}$ aquades ditambah 4 tetes $\mathrm{HCl} 1: 1 \mathrm{di}$ dalam beaker glass dan dicelupkan kertas kurkuma.

\section{Pembuatan Pembanding}

Boraks 0,001 $\mathrm{mL}$ dimasukkan ke dalam beaker gelas yang berisi air dan aduk larutan boraks. Teteskan pada kertas kurkumin yang sudah disiapkan. Amati perubahan warna pada kertas kurkumin. Warna rossasianin yang dihasilkan tersebut akan dipergunakan sebagai kontrol positif.

\section{Identifikasi Boraks pada Sampel}

Identifikasi boraks pada sampel dapat dilakukan dengan 2 cara:

\section{Identifikasi boraks dengan cara tidak}

\section{diabukan}

Sebanyak 10 gram sampel digerus halus di atas lumpang, lalu tambahkan aquades, kemudian dimasukkan ke dalam beaker glass $250 \mathrm{~mL}$, kemudian ditambahkan 4 tetes asam klorida. Celupkan kertas kurkuma pada sampel, jika sampel mengandung borak akan berubah warna kuning menjadi warna rossasianin (merah jingga).

\section{Identifikasi boraks dengan cara diabukan}

Sebanyak 10 gram sampel digerus halus di atas lumpang, lalu tambahkan aquades, kemudian dimasukkan ke dalam beaker glass $250 \mathrm{~mL}$, kemudian dimasukkan ke dalam oven setelah itu ditambahkan kalsium karbonat, kemudian masukkan ke dalam furnace hingga menjadi abu dan ditambahkan asam klorida. Celupkan kertas kurkumin pada sampel, jika sampel mengandung borak akan berubah warna kuning menjadi warna rossasianin (merah jingga).

\section{Analisis Data}

Hasil penelitian identifikasi boraks pada makanan pempek yang dijual di jalan Durian Kelurahan Labuh Baru Kecamatan Payung Sekaki Pekanbaru. Data yang diperoleh penelitian disajikan dalam bentuk tabel dan dibahas secara kualitatif.

\section{HASIL DAN PEMBAHASAN}

\section{Hasil}

Analisa yang dilakukan terhadap sampel pempek yang diambil dari satu pedagang yang terdapat di jalan Durian Kelurahan Labu Baru Kecamatan Payung Sekaki Pekanbaru pada bulan Februari 2015 sebagai berikut: 
Tabel 1. Hasil Penelitian Sampel Pempek yang Tidak Diabukan

\begin{tabular}{clcc}
\hline No & Sampel & Warna & Hasil \\
\hline 1 & Blanko & Orange & Negatif \\
2 & Pembanding & Rossasianin & Positif \\
3 & Sampel & Rossasianin & \\
& Pengulangan I & Rossasianin & Positif \\
& Pengulangan II & Rossasianin & Positif \\
& Pengulangan III & & Positif \\
\hline
\end{tabular}

Tabel 2. Hasil Penelitian Sampel Pempek yang Diabukan

\begin{tabular}{clcc}
\hline No & Sampel & Warna & Hasil \\
\hline 1 & Blanko & Orange & Negatif \\
2 & Pembanding & Rossasianin & Positif \\
3 & Sampel & & \\
& Pengulangan I & Rossasianin & Positif \\
& Pengulangan II & Rossasianin & Positif \\
& Pengulangan III & Rossasianin & Positif \\
\hline
\end{tabular}

Berdasarkan identifikasi boraks pada makanan pempek yang dijual pedagang di Jalan Durian Kelurahan Labuh Baru Kecamatan Payung Sekaki didapatkan hasil penelitian dengan menggunakan metode uji warna larutan kurkuma pada sampel, yang dilakukan sebanyak tiga kali pengulangan hasilnya positif $(+)$ mengandung boraks. Hal ini dapat dilihat dari bentuk, tekstur, dan warna pada pempek, diantaranya sedikit keras, kenyal, dan tahan lama.

Identifikasi boraks pada sampel dapat dilakukan dengan 2 cara: yang pertama dengan tidak diabukan, yaitu sebanyak 10 gram sampel digerus halus di atas lumpang, lalu tambahkan aquades, kemudian dimasukkan ke dalam beaker glass $250 \mathrm{~mL}$, kemudian ditambahkan 4 tetes asam klorida. Celupkan kertas kurkuma pada sampel, diperoleh sampel mengandung borak akan berubah warna kuning menjadi warna rossasianin (merah jingga).

Cara yang kedua dengan diabukan, bertujuan untuk menghilangkan zat organik yang dapat mengganggu pemeriksaan, yaitu sebanyak 10 gram sampel digerus halus di atas lumpang, lalu tambahkan aquades, kemudian dimasukkan ke dalam beaker glass $250 \mathrm{~mL}$, kemudian dimasukkan ke dalam oven setelah itu ditambahkan kalsium karbonat, kemudian masukkan ke dalam furnace hingga menjadi abu dan ditambahkan asam klorida. Celupkan kertas kurkumin pada sampel, diperoleh sampel mengandung borak akan berubah warna kuning menjadi warna rossasianin (merah jingga). Dari dua cara kerja yang telah dilakukan dapat digunakan untuk mengidentifikasi boraks pada makanan. 
Seseorang yang mengkomsumsi makanan yang mengandung boraks tidak akan langsung mengalami dampak buruk bagi kesehatan, tetapi senyawa tersebut diserap dalam tubuh secara kumulatif. Selain melalui saluran pencernaan, boraks dapat diserap melalui kulit. Dosis yang cukup tinggi dalam tubuh akan menyebabkan munculnya gejala pusing-pusing, muntah, dan kram perut. Pada anak kecil dan bayi, bila dosis dalam tubuhnya sebanyak 5 gram atau lebih dapat menyebabkan kematian, sedangkan untuk orang dewasa kematian terjadi pada dosis 10 sampai 20 gram (Endrinaldi, 2006).

Dengan adanya hal seperti ini diharapkan pada masyarakat harus lebih berhati-hati dalam memilih makanan yang akan dikonsumsi. Kenali bentuk dan ciri-ciri makanan tersebut untuk memastikan mengandung bahan pengawet atau tidak..

\section{KESIMPULAN DAN SARAN}

\section{Kesimpulan}

Dari penelitian identifikasi boraks pada pempek yang diambil dari satu pedagang yang dilakukan tiga kali pengulangan didapatkan hasil positif mengandung borak.

\section{Saran}

1. Diharapkan kepada penelitian selanjutnya agar dapat menghitung kadar boraks pada pempek dengan metode spektrofometri (UV).

2. Diharapkan kepada masyarakat lebih berhati-hati lagi dalam memilih makanan siap saji seperti pempek.

\section{DAFTAR PUSTAKA}

Alsuhendra. \& Ridawati. 2013. Bahan Toksik Dalam Makanan, PT Remaja Rosdakarya. Bandung.

Arisman. 2002. Keracunan Makanan. Buku Kedokteran. Jakarta

Cahyadi, W. 2009. Analisa dan Aspek Kesehatan Bahan Tambahan Pangan: Edisi Kedua. Bumi Aksara. Jakarta

Endrinaldi. 2006. Identifikasi dan Penetapan Kadar Boraks pada Mie Basa yang Beredar di Beberapa pasar Di Kota Padang. Fakultas Kedokteran; Padang.

Hariadi. 2009. Petunjuk Sederhana Memproduksi Pangan yang Aman. Dian Rakyat. Jakarta

Nasution, A. 2009. Analisa Kandungan Boraks pada Lontong di Kelurahan Padang Bulan Kota Medan. Skripsi FKM USU, Medan

Oliveoile. 2008. Boraks (online), (https://www.scribd.com/.../13627 0286, diakses 25 November 2014) Pengertian Pempek (online), (http://pempekklenjar.com, diakses 16 November 2014) 
Rohman, A. Sumantri. 2007. Analisis Makanan. Gadjah Mada University Press. Yogyakarta

Saparianto \& Hidayati. 2006. Gejala Klinis Keracunan Boraks (online), http://www.scribd.com/.../136270 286, diakses 25 November 2014)

Sartono. 2001. Racun dan Keracunan. Widya Medika. Jakarta Sejarah Pempek Palembang (online), http://www.scribd.com/mobile/.../ $\underline{86152112}$, diakses 16 November 2014)

Tristianingsih, N. 2012. Identifikasi Methanil Yellow dalam es sirup. Pekanbaru.

Widyaningsih, T, D, dan Murtini, ES, 2006. Alternatif Pengganti Formalin Pada Produk Pangan. Trubus agrisarana, Jakarta. 